\title{
Guidelines and quality outcomes in cancer surgery: Goals, expectations and reality television
}

\author{
Stephen E. Pautler, MD FRCSC
}

Southwest Surgical Oncology Lead, Cancer Care Ontario, Divisions of Urology and Surgical Oncology, Departments of Surgery and Oncology, Western University, London, ON

See related article on page 442.

Cite as: Can Urol Assoc J 2012;6(6):446-7. http://dx.doi.org/10.5489/cuaj.12326

S urgery is defined as: "the branch of medicine concerned with (the) treatment of injuries or disorders of the body by incision, manipulation or alteration of organs with the hands or instruments." ${ }^{11}$ As such, surgery is implicitly dependent on human qualities, such as the skills, training and experience of the surgeon within the context of the patient's disease. Within our specialty, few procedures are as challenging to surgeons and pathologists as radical prostatectomy. The goals of this procedure are oncologic control of the disease, while preserving the functional outcomes of urinary continence, and baseline erectile function. If these goals are met, the assumption is that the patient can enjoy a long disease-free life with preservation of his quality of life. This is easier said then done.

Increasingly, surgical outcomes are being measured and reported, not only in the traditional sense of academic publications from centres of excellence, but also on a health care system basis. In Canada, most provinces are reporting some measures as a means of assessing surgical quality. Which metrics matter is debatable. Is it the surgical wait time? Or radical prostatectomy positive margin rates for $\mathrm{T} 2$ disease? The number of blood transfusions received by a patient population? Consensus among all stakeholders will continue to redefine the measures of quality.

Cancer Care Ontario (CCO) is the provincial agency that guides the Ministry of Health and Long Term Care (MOHLTC) on the delivery of cancer services within the province. The mission statement of CCO is to improve the performance of cancer care by driving quality, accountability, innovation and value. ${ }^{2}$ The other agency that influences cancer care in Ontario is the Cancer Quality Council of Ontario (CQCO). This group reports quality measures to the MOHLTC and the public with yearly report cards. For example, the T2 positive margin rates for Ontario are reported by region and are compared to the provincial benchmarks and averages. As such, an individual surgeon or hospital can check how well their performance is in comparison to their provincial peers.

One of CCO's strategies has been to assemble groups of physicians who care for specific disease sites and engage them in the development of guidelines. Radical prostatectomy was one of the key procedures identified for quality optimization in the province due to the high volume of cases, the number of centres performing these cases, and the impact of surgical and pathologic techniques on the outcomes. The CCO guideline was published in $2008^{3}$ and is the basis for the analysis found in the manuscript by Webster and colleagues. ${ }^{4}$

These authors report a retrospective analysis of 133 cases of radical prostatectomy performed at their community hospital over a 2-year span. Using the provincial guidelines, they correctly conclude that appropriate patient outcomes, as defined by the CCO guidelines, are feasible within smaller regional institutions. While there are limitations with this paper based on the retrospective nature of the work, I strongly congratulate these authors on their undertaking. All surgeons and institutions should perform similar quality reviews of their own outcomes. This will allow ongoing reflection, which in turn could lead to modifications in technique, patient selection and care pathways, resulting ultimately in improved care for patients. Thus, future patients served in such communities can be reassured that their surgeons are meeting performance expectations. Indeed, in some jurisdictions, such as Australasia, surgeons are required to perform regular outcome analysis of their practices to maintain their certification. $^{5}$

Agencies, such as CCO and CQCO, have responsibilities to provide leadership in quality initiatives and to provide feedback to surgeons and hospitals in a collaborative fashion. Guidelines are great to create, but in reality, the transla- 
tion to better patient care is complex and needs continued re-evaluation. Our society is demanding accountability from our health care system. Perhaps, this is a reflection of a decade of reality television where you can watch and then vote for your favourite singer, dancer, or watch people make duck calls or wrestle alligators. As surgeons, we have many responsibilities, including to strive for the best outcomes, stay current, manage limited resources and to review our outcomes. Many of these skills are not part of our medical education curriculum; they are learned on the job. We need to be active participants in defining and reporting surgical quality as we move forward.

Competing interests: Dr. Pautler receives a salary from Cancer Care Ontario in his role as Southwest Surgical Oncology Lead.

\section{References}

1. The Oxford Dictionary and Thesaurus. Oxford Press, New York, NY; 1996:1538.

2. Cancer Care Ontario: Vision, Mission and Guiding Principles. https://www.cancercare.on.ca/about/ who/vision/. Accessed November 26, 2012.

3. Chin JL, Srigley J, Mayhew LA, et al. Guideline for optimization of surgical and pathological quality performance for radical prostatectomy in prostate cancer management: evidentiary base. Can Urol Assoc J 2010; : : 13-25

4. Webster TM, Newell C, Amrhein JF, et al. Cancer Care Ontario Guidelines for radical prostatectomy: striving for continuous quality improvement in community practice. Can Urol Assoc J 2012;6:442-5. Epub 2011 Sept 8. http://dx.doi.org/10.5489/cuaj.10195. [Epub ahead of print]

5. Surgical Audit and Peer Review (3 ${ }^{\text {td }}$ Ed). The Royal Australasian College of Surgeons, Melbourne; 2008.

Correspondence: Dr. Stephen E. Pautler, St. Joseph Health Care, P 0 Box 5777 Stn B, 268 Grosvenor St., London, 0N N6A 4V2; stephen.pautler@sihc.london.on.ca 